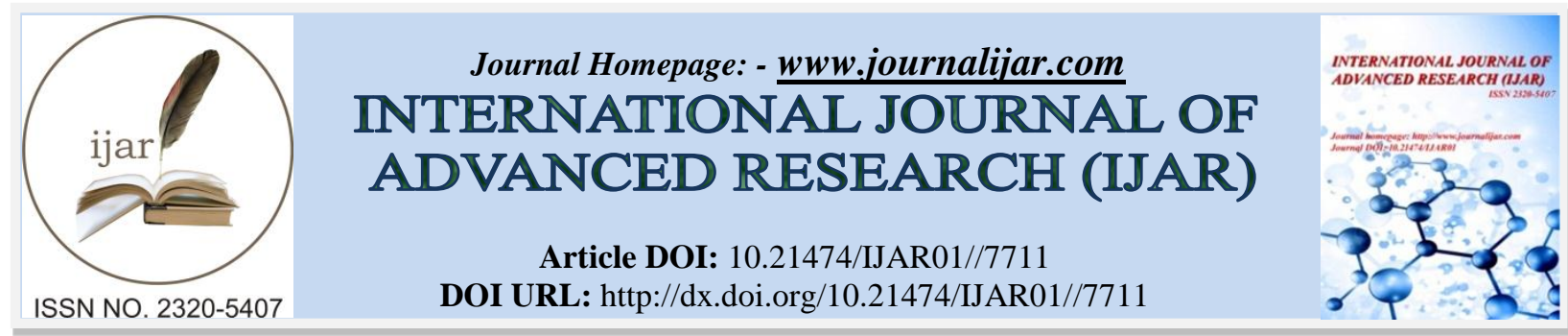

RESEARCH ARTICLE

\title{
IDENTIFYING AND MITIGATING SUDDEN UNEXPECTED DEATH IN EPILEPSY (SUDEP) RISK FACTORS. CRITICAL APPRAISAL.
}

Bashayer Al Zayed. MD.

\section{Manuscript Info}

\section{Manuscript History}

Received: 20 July 2018

Final Accepted: 26 August 2018

Published: September 2018

\begin{abstract}
In the article, Watkins and colleagues observe that SUDEP causes a lot of deaths in people diagnosed with epilepsy. Hence, in reviewing the current understanding of the risk factors, static or modifiable, for SUDEP they reveal how they are managed and show areas that need more evidence in order to show that the technologies are more safe and efficacious. The main challenge in dealing with SUDEP, as highlighted by Watkins and colleages, is that there is inadequate robust research into the matter, inadequate pathological mechanisms, management strategies and variance in methodologies that result in obstacles on how and what to discuss with the individuals suffering from chronic epilepsy.
\end{abstract}

\section{Introduction:-}

The Identifying and mitigating Sudden Unexpected Death in Epilepsy (SUDEP) risk factors is a review article. This is because unlike any other original research article, it does not report original research findings from the field. The researcher and authors of the article bases their writings based on findings from other articles that have been published in the past. Hence, in general, it summarizes the findings of an existing literature material on the topic of interest. This is in an attempt to elaborate on the current state of understanding the subject at hand. There are various types of review articles and they include a narrative review, a systematic review, and meta-analysis review paper. A narrative review article will explain the findings on a given topic based on all research available on the topic of discussion. On the other hand, a systematic review article examines scientific journal articles that are already published based on a particular question. Finally, the meta-analysis review article will combine findings and compare them in order to explore the impact a given intervention or mode of treatment has in the modern society. Identifying and mitigating Sudden Unexpected Death in Epilepsy (SUDEP) risk factors is a narrative review article that summarizes the findings on exitsing literature about SUDEP hence allowing the readers understand the current findings on the condition without having to read all works that have been published so far.

In the article, Watkins and colleagues observe that SUDEP causes a lot of deaths in people diagnosed with epilepsy. Hence, in reviewing the current understanding of the risk factors, static or modifiable, for SUDEP they reveal how they are managed and show areas that need more evidence in order to show that the technologies are more safe and efficacious. The main challenge in dealing with SUDEP, as highlighted by Watkins and colleages, is that there is inadequate robust research into the matter, inadequate pathological mechanisms, management strategies and variance in methodologies that result in obstacles on how and what to discuss with the individuals suffering from 
chronic epilepsy. In this article longitdinal risks are assessed using the standard risk assessment tools as the authors discuss the technological advancements used to measure seizures and risks of SUDEP.

\section{Research Question}

What are the risk and mitigating factors associated with SUDEP for people with chronic epilepsy?Can the risks associated with SUDEP be reduced as part of managing epilepsy effectively? Can health care professionals and service providers aim for Gold Standard of care when approaching SUDEP risk management? Can all people with epilepsy receive a certain level of standardized minimal care that is not only practical but also effective to implement?

\section{My Clinical Question}

Maternal feeding and its relationship to neonatal seizures

\section{PICO analysis}

Population:- This is a review article. The authors discuss risks factors associated with SUDEP and reveal the details of all available research on the matter. About 95 articles were reviewed in the paper and each identified based on the contribution it has about epilepsy and sudden deaths due to the seizures.

Interventions:- Not applicable in this case.

Comparison groups:- Not Applicable. There are no comparison groups involved in this review article except for analysis of findings by different research. Literature is reviewed and important points from each publication presented in summary as per the objective of the paper.

Outcome:- Various themes, risks and factors associated with SUDEP are highlighted with the authors recognizing that various attempts have been made in the past to provide a list ranking various risk factors for SUDEP. The authors also discuss some of the risk factors that can be modified and if well managed with the appropriate tools for seizure and risk management, can have less impact on patients with chronic epilepsy. They highlight factors that should be considered by all people and some include access to proper care from the basic/ primary services to tertiary care, availability of resources to manage epilepsy, and implementation of the necessary approach by medical professionals. Watkins and his colleagues also highlight the desired standard care for epileptic patients that aim at reducing the frequency of seizure to about three per year at most. The discussion leads to presentation of the practical and acceptable clinical practices that can be implemented in order to obtain minimum care standards.

\section{CASP Appraisal Guide}

\section{CASP Appraisal Guide}

Section A:-Are the results valid?

1. Was there a clear $\quad$ i. Aims of the paper

statement of the aims

of the research?

Yes, there is a clear statement of the aims of the research article by the authors. In the abstract, they start by producing an introduction, highlighting areas to be covered and an expert commentary. The title is also clear enough to reveal the objective of the article, which is identification, and mitigation of sudden unexpected death in epilepsy (SUDEP) risk factors.

Other than that, the authors do not mention the aim of the study later in the paper clearly like it in a thesis statement in the introduction section or in a section of its own. Instead, the aims of the paper are incorporated within the paper by the manner in which the authors present their findings directly. Immediately after the brief introduction, they start with the review analysis, highlighting the risk factors and discussing the mitigation aspects. The conclusion suggests the objective of the paper has been met by revealing that as per the finding from other scholars, SUDEP risk factors can be modified easily and as many scholars have discovered, the most important aspect when managing the risk factors associated with SUDEP is to control the seizures.

ii. Why was it important?

Identifying and mitigating risk factors of SUDEP has been considered important because the prevalence of active epilepsy continues to increase in the modern society and with every diagnosis, comes with increased chances of the patients dying and 


\begin{tabular}{|c|c|}
\hline & $\begin{array}{l}\text { getting serious injuries from all manner of causes. Statistics in UK reveal thata high } \\
\text { percentage of the people in epilepsy population experience seizure and hence they face } \\
\text { increased risks. The life expectancy of the same people reduces by } 10 \text { years or more } \\
\text { compared to the general population. The increased mortality rate is directly linked to } \\
\text { the causes of the epileptic condition in the patient, the occurrence of the seizures, and } \\
\text { the status of the patient themselves. The subject was considered important because } \\
\text { while various studies have been carried out in the recent times, there is lack of robust } \\
\text { research into the mechanisms used for pathological purposes. Further, Watkins and } \\
\text { colleagues acknowledge that for people to succeed in epileptic management, they } \\
\text { should focus on reducing the risks, and defining the gold standards of care that aim at } \\
\text { focusing on how and when to approach SUDEP risk management aspects. } \\
\text { iii. } \\
\text { According to Watkins and colleagues, SUDEP is a result of a number of accumulated } \\
\text { effects of multifactorial risk aspects and situations that are mostly triggered by the } \\
\text { peri-ictal concurrence of a number of predisposing and precipitating factors. } \\
\text { Furthermore, the changes witnessed in risk factors of SUDEPcould be attributed to } \\
\text { other confounding factors. Since some of the risk factors can be modified, } \\
\text { understanding how to achieve good seizure management and how to assess risks is } \\
\text { critical. }\end{array}$ \\
\hline $\begin{array}{l}\text { 2. Is a qualitative } \\
\text { methodology } \\
\text { appropriate? }\end{array}$ & $\begin{array}{l}\text { Can't Tell. The research seeks to interpret findings presented by other researchers in } \\
\text { the recent times. They focus on the available resources on seizure management, } \\
\text { SUDEP as well as epilepsy and use the information in earlier scholarly material to } \\
\text { identify the risk factors as well as explore the mitigation of SUDEP risk aspects. While } \\
\text { literature review is not a qualitative method, it is not a quantitative design either and } \\
\text { hence it is hard to tell is qualitative research design is the right methodology for } \\
\text { addressing the research goal. In any case, the research does not seek o interpret or } \\
\text { illuminate the actions and/ or subjective experiences of research participants. }\end{array}$ \\
\hline \multicolumn{2}{|l|}{ Is it worth continuing? } \\
\hline $\begin{array}{l}\text { 3. Was the research } \\
\text { design appropriate to } \\
\text { address the aims of } \\
\text { the research? }\end{array}$ & $\begin{array}{l}\text { Yes, the research design in this case is literature review analysis and it is the most } \\
\text { appropriate methodology used to address the aims of the research study by Watkins } \\
\text { and colleagues. While the authors of the article have not been able to justify the } \\
\text { research design in the paper while presenting their findings, the expert reviews and } \\
\text { discussions highlighted in the paper confirm the need for the review and its } \\
\text { appropriateness now. Watkins and colleagues are more interested in presenting their } \\
\text { review than discussing or justifying the methodologies, they plan to use and how they } \\
\text { will use them. }\end{array}$ \\
\hline $\begin{array}{l}\text { 4. Was the recruitment } \\
\text { strategy appropriate } \\
\text { to the aims of the } \\
\text { research? }\end{array}$ & $\begin{array}{l}\text { Can't tell. While there are no participants involved in the research study and the review } \\
\text { presented by Watkins and his colleagues, the researchers use previously published } \\
\text { research studies and resources to present their findings. They review those materials } \\
\text { and discuss the findings already presented to the public in order to summarize for the } \\
\text { general population, what is currently known and understood about the risk factors or } \\
\text { SUDEPas well as the mitigation mechanisms. In identifying these materials, they } \\
\text { hardly explain how the resources were identified, selection criteria, exclusion } \\
\text { mechanisms, or the database where they were found. Therefore, it is hard to tell if the } \\
\text { resources used were the appropriate ones. However, based on the information in the } \\
\text { article, the researchers had adequate information to discuss their findings and highlight } \\
\text { their details to the readers. The identification of the risk factors is comprehensive } \\
\text { enough and the in highlighting the mitigation factors, the researchers are clear in their } \\
\text { discussions and providing expert opinion on the matter. This thus means that they } \\
\text { reviewed appropriate articles and they were keen to select the most appropriate } \\
\text { resources to provide access to the type of knowledge sought for the study. } \\
\text { In the reference list, the researchers have also highlighted the significance of some of } \\
\text { the articles reviewed in the paper. This information is crucial towards understanding } \\
\text { how important those resources are to providing information needed for the study. } \\
\text { There is no explanation as to why the significance of some articles is highlighted and } \\
\text { not for others. }\end{array}$ \\
\hline
\end{tabular}




\begin{tabular}{|l|l|}
\hline $\begin{array}{l}\text { 5. Was the data } \\
\text { collected in a way } \\
\text { that addressed the } \\
\text { research issue? }\end{array}$ & $\begin{array}{l}\text { Yes, the data collected for this research study was done in a way that addresses the } \\
\text { research issue. While the researchers do not discuss the settings for the data collection } \\
\text { in the paper, they do not justify the methodologies used, and do not reveal how the data } \\
\text { was collected in a clear manner, the findings in them are clear and addresses the issue } \\
\text { of discussion. The researchers have presented 10 sections in the paper and in each, they } \\
\text { clearly discuss issues relevant to the aims of the paper and leading to the identification } \\
\text { of the risks and mitigation factors of SUDEP. } \\
\text { The methodologies were not modified during the study and the researcher has not } \\
\text { discussed the saturation of the data but the form of data collected from the reviews is } \\
\text { clear. }\end{array}$ \\
\hline $\begin{array}{l}\text { Has the relationship } \\
\text { between researcher } \\
\text { and participants been } \\
\text { adequately } \\
\text { considered? }\end{array}$ & $\begin{array}{l}\text { No. This is not applicable in this case because this paper by Watkins and colleagues } \\
\text { did not involve participants in the field or collection of raw data from the field. It was a } \\
\text { review article and it presented research findings by previous scholars. Therefore, the } \\
\text { researcher did not critically examine their own role in the study, the potential bias, and } \\
\text { the influence during the formation of research questions and data collection including } \\
\text { sample recruitment and choice of the location. } \\
\text { In addition, it is not clear how the researchers responded to the events during the study } \\
\text { and whether they considered the implications of any changes in the research design. }\end{array}$ \\
\hline
\end{tabular}
Section B:-What are the results?

7. Have ethical issues $\quad$ Can't tell. In the paper, there is mention of ethical issues having been taken into been taken into consideration? consideration. In any case, since it is a review article, there is no need for explanation on how the details of the study would be explained to the participant for the readers to be able to assess whether ethical standards were maintained. Further, there is no need for the researcher to discuss the issues raised by the study such as issues around informed consent or confidentiality or how the researchers were able to handle the effects of the study in the participants during or after the study was carried out.

The review of the resources is straight forward and in the article, the researchers only focus on summarizing the findings of the earlier scholars and help the readers understand what is current understood by the community of researchers about the identity of risks and the mitigation aspects of SUDEP.

8. Was the data analysis sufficiently rigorous?

Yes, the data analysis was sufficiently rigorous in this given article. This is because there is an in-depths presentation of review findings from the first section of the paper to the last. The paper is divided into different subsections with each discussing a given subtitle that helps the researchers achieve their aim in the paper.

Thematic analysis was clearly used to analyze and review the findings earlier scholars but it is unclear how the categories were derived from the data and resources identified for review. Hence, sufficient data was presented to support the findings of the research study. This is clear from the conclusions drawn and the expert comments discussed in the paper. However, it is hard to tell to what extent contradictory data has been taken into account. This is because the researchers have not critically examined their own role in the review analysis process. In addition, it is clear that the researchers did not perform a potential bias analysis or explain how their actions or interests during the review analysis process influenced the selection of data, analysis and presentation.

Watkins and colleagues however, present a declaration of interest for each author involved in the study. In a brief section in the paper, they explain the role of each author, status in the community, job and interest in the matter of SUDEP and seizures. This declaration is critical as while it is not clearly explaining the ethical aspects, it eliminates doubts of biasness among the researchers. The relevant affiliation and involvement of the authors is clearly due to their jobs and membership in different panels and associations. They obviously receive zero financial gain or experience zero financial conflicts with the subject matter discussed in the article thus the information discussed in this article is reliable and free from possible biasness resulting from researchers.

9. Is there a clear $\quad$ Yes, there is a clear statement of the findings in the article. From the first section of the statement of findings? paper, the researchers clearly state their findings and summarize the details from the other resources that they were able to review. However, in the abstract, introduction, 


\begin{tabular}{|c|c|}
\hline & $\begin{array}{l}\text { expert commentary, and conclusion sections, they are clearer while presenting their } \\
\text { summaries and the readers are able to assess whether the objectives of the article have } \\
\text { been met by simply reviewing these sections. } \\
\text { In addition, Watkins and colleagues have another last section, the key issue subsection } \\
\text { and here, they present point-to-point highlights of matters raised in the matter about } \\
\text { SUDEP and risk factors. The mitigation aspect is also highlighted hence summarizing } \\
\text { the need for the research study and presentation of the review in the modern times. }\end{array}$ \\
\hline \multicolumn{2}{|c|}{ Section C:-Will the results help locally? } \\
\hline $\begin{array}{l}\text { 10. How valuable is the } \\
\text { research? }\end{array}$ & $\begin{array}{l}\text { The findings presented in this research article are very important to the researchers and } \\
\text { the general community despite the fact that the researchers have not clearly discussed } \\
\text { the contributions this study has had to the community. They are careful to mention the } \\
\text { relevance of these findings in relation to the current medical practice in various } \\
\text { subsections in the paper. In fact, they explicitly discuss measures that the medical } \\
\text { professionals can implement that can make the management of epilepsy easier and less } \\
\text { risky for the patients. This is in a subsection under desirable standard care and } \\
\text { minimum care standards. } \\
\text { Watkins and colleagues have also discussed areas that can be refocused in the future to } \\
\text { ensure that SUDEP is no longer a major cause of mortality for epileptic patients. In the } \\
\text { final section, they present the five-year view where they highlight the main challenges } \\
\text { that might not be overcome if more is not done in the future. To them, there is still a lot } \\
\text { to do aboutSUDEP since even in developed nations like UK and US the information on } \\
\text { what to discuss about SUDEP with patients is unclear or scanty. They consider that the } \\
\text { findings for this study cannot be ignored since for many people, epilepsy could be } \\
\text { chronic and lifelong condition. Since the mortality rate has been increasing for years, } \\
\text { there is need to work on risk control measures and mechanisms that can reduce } \\
\text { frequency of seizure to less than three instances in a year. } \\
\text { In concluding the review, Watkins and colleagues are clear in highlighting steps that } \\
\text { should be taken in the next few years in order to further enhance awareness and } \\
\text { understanding towards SUDEP. They discuss how trials on antiepileptic drugs and } \\
\text { surgical operations could help mitigate SUDEP by controlling the frequency of seizure. } \\
\text { Further, they also discuss whether and how the information in this paper can be } \\
\text { transferred to other populations while also considering other ways in which the current } \\
\text { and future stakeholders in medical field could use the research and review findings. }\end{array}$ \\
\hline
\end{tabular}

\section{Citation:-}

Watkins, L., Sander, L., \& Shankar, R. (2018). Identifying and mitigating Sudden Unexpected Death in Epilepsy (SUDEP) risk factors. Expert Review of Neurotherapeutics, p.1-10; DOI: 10.1080/14737175.2018.1439738. 